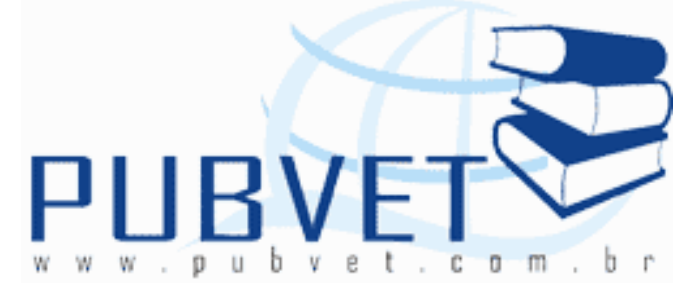

PUBVET, Publicações em Medicina Veterinária e Zootecnia.

\title{
Aspectos morfológicos e fisiológicos de glândulas mamárias de fêmeas bovinas - revisão de literatura
}

Guilherme Dias Araujo1, Karina Barbosa de Souza², Luísa Anastácio dos Santos de Oliveira ${ }^{3}$, Raphaella Paula Ribeiro ${ }^{3}$

${ }^{1}$ Médico Veterinário graduado pela Universidade de Uberaba, Uberaba, Minas Gerais, Brasil. E-mail: guilherme.d.a@bol.com.br.

${ }^{2}$ Medica Veterinária Residente em Clínica Cirúrgica, Hospital Veterinário de Uberaba (HVU), Uberaba, Minas Gerais, Brasil.

${ }^{3}$ Graduando em Medicina Veterinária, Universidade de Uberaba, Uberaba, Minas Gerais, Brasil.

\section{Resumo}

As glândulas mamárias são estruturas do corpo de mamíferos constituídas por quantidades variáveis de estruturas glandulares que, em fêmeas, promove uma secreção glandular que é responsável por alimentar recém-nascidos da espécie. No caso de bovinos, essa secreção é amplamente utilizada na alimentação humana. A glândula mamária de fêmeas bovinas (úbere) tem localização inguinal, com metades direita e esquerda distintas; cada uma com um quarto anterior e posterior. Cada metade é independente quanto a suprimento sanguineo, nervoso, drenagem linfática e aparelho suspensor. 0 crescimento mamário, sua diferenciação e lactação (secreção e saída do leite) envolvem os processos de mamogênese, lactogênese a galactopoese. Vários 
hormônios participam do desenvolvimento das fases anteriormente citadas, como estrogênio, progesterona, somatotropina, prolactina, insulina, paratormônio, hormônio adrenocorticotrópico e hormônio tireoestimulante, assim como $\mathrm{T}_{3}$ e $\mathrm{T}_{4}$.

Palavras-chave: úbere, bovino, desenvolvimento, hormônio

\title{
Morphological and physiological aspects of bovine females mammary glands - literature review
}

\begin{abstract}
The mammary glands are body structures of mammals consisting of varying amounts of glandular structures, which, in females, promotes a glandular secretion responsible for feeding newborn of the species. In the case of cattle, this secretion is widely used as human food. The mammary glands of cows (udder) has inguinal location, with separate left and right halves, each with an anterior and posterior quarter. Each half is independent as the blood supply, nervous, lymphatic drainage and suspensory apparatus. The mammary growth, differentiation and lactation (secretion and output of milk) involves mammogenesis, galactopoiesis and lactogenesis processes. Several hormones participate in the development of the phases previously mentioned, such as estrogen, progesterone, somatotropin, prolactin, insulin, parathyroid hormone, adrenocorticotropic hormone and thyroid-stimulating hormone, as well as T3 and $\mathrm{T} 4$.
\end{abstract}

Keywords: udder, cattle, development, hormone

\section{REVISÃO DE LITERATURA}

\section{ASPECTOS MORFOLÓGICOS}

A glândula mamária é constituída, no seu conjunto, por um número variado de unidades glandulares distribuídas bilateralmente, simétricas e 
paralelas à linha mediana ventral do tronco, chamada na fêmea bovina de úbere (BRAGULLA \& KÖNIG; 2004).

Sob o ponto de vista anatômico-microscópico, a glândula mamária é uma glândula sudorípara exócrina modificada, tubuloacinosas compostas com tipo secretório holomerócrino ou apócrino, separadas por tecido conjuntivo (FEITOSA, 2008; BRAGULLA \& KÖNIG, 2004).

A glândula mamária está dividida em unidades glandulares distribuídas simetricamente de cada lado da linha mediana ventral do tronco, as linhas mamárias direita e esquerda, separadas pelo sulco intermamário. Cada conjunto de glândulas é constituído por um corpo glandular e um teto, a papila mamária (sendo que cada teto drena uma glândula separada). Ambos, corpo e teto, recobertos por pele modificada, sendo glabra nas papilas, apresentando uma concentração de pêlos sobre o corpo da mama variando conforme a espécie animal (BRAGULLA \& KÖNIG, 2004; DAVIDSON \& STABENFELDT, 2008; PARK \& LINDBERG, 2007).

$\mathrm{Na}$ fixação da glândula mamária atuam os folhetos superficiais e profundos da fáscia superficial do tronco, que constituem o sistema de sustentação da mama. Este é constituído pela lâmina lateral superficial e pela lâmina medial elástica interna, das quais, por sua vez, se projetam as lamelas de sustentação no parênquima da glândula (BRAGULLA \& KÖNIG; 2004).

A glândula mamária é constituída de dois tecidos diferentes: o parênquima e o estroma. O parênquima glandular contém as unidades morfofuncionais (adenômeros) encarregados da secreção láctea. O estroma glandular, por sua vez, é o tecido que abriga capilares sanguíneas, células mioepiteliais e fibras reticulares; sendo então, o tecido conjuntivo intersticial intraparenquimatoso (BRAGULLA \& KÖNIG, 2004; DAVIDSON \& STABENFELDT, 2008; FEITOSA, 2008;).

A mama é dividida em vários lobos (parênquima) por tecido conjuntivo denso e adiposo, com vasos e nervos (estroma). Embora o conjunto de lobos seja chamado frequentemente de glândula mamária, cada lobo é de fato uma 
glândula mamária, com sua parte secretora e seu ducto excretor próprio (JUNQUEIRA \& CARNEIRO; 1999).

Abundante tecido conjuntivo penetra em cada lobo, dividindo-o em lóbulos e envolvendo cada unidade tubuloacinosa compostas. Cada um desses lóbulos consiste em 200 alvéolos e possuem $1 \mathrm{~mm}$ de comprimento (DYCE, SACK, WENSING, 1997; FEITOSA, 2008).

Os lóbulos da glândula mamária são compostos por vários alvéolos glandulares unidos uns com os outros e recobertos internamente por um epitélio isoprismático de uma só camada. São eles que produzem e secretam o leite. Essa construção é típica para a organização de uma glândula de armazenagem láctea (BRAGULLA \& KÖNIG; 2004).

No espaço basal do seio glandular, abrem-se vários ductos lactíferos revestidos internamente por um epitélio estratificado pavimentoso. À medida que o ducto se aprofunda na mama, seu epitélio se torna cada vez mais fino, com menor número de camada de células, até apresentar apenas duas camadas de células cilíndricas. Mais próximo às unidades secretoras, o epitélio do ducto se torna cúbico simples. Na parede dos ductos existem células musculares lisas (JUNQUEIRA \& CARNEIRO; 1999).

O seio lactífero glandular torna-se acessível através do óstio externo da papila mamária, e seu ducto papilar é revestido internamente por um epitélio mucoso estratificado e queratinizado. O seio glandular é um espaço de coleta e armazenamento do leite, comunicando-se com um segmento distal da papila, a porção papilar ou seio lactífero. Esta se apresenta como uma cisterna na extremidade distal do canal do teto (BRAGULLA \& KÖNIG, 2004; PARK \& LINDBERG, 2007).

A papila mamária, ou teto, tem forma cilíndrico-cônica. Externamente é revestida por epitélio estratificado pavimentoso, queratinizado, que se continua com o da pele vizinha. Seu epitélio repousa sobre tecido conjuntivo, com fibras musculares lisas. As fibras musculares estão dispostas circularmente aos redor dos ductos lactíferos e paralelamente aos mesmos, quando estes atravessam a papila para irem abrir-se no seu ápice (JUNQUEIRA \& CARNEIRO; 1999). 
O úbere da fêmea bovina é constituído por quatro glândulas mamárias individuais chamadas de quartos mamários (quartos mamários anteriores direito e esquerdo; e quartos mamários posteriores direito e esquerdo); os quais estão fixados na parede ventral da região inguinal. Cada uma das quatro glândulas mamárias é representa unidades glandulares independentes. (BRAGULLA \& KÖNIG, 2004).

\section{Sistema de Sustentação}

Uma das adaptações anatômicas importantes do úbere que permite às vacas leiteiras carregar grandes quantidades de leite é o desenvolvimento do sistema suspensor do úbere (DAVIDSON \& STABENFELDT, 2008).

Entre os ligamentos suspensores da glândula mamária dos bovinos, cabe destacar os seguintes: ligamento suspensor lateral da mama (tiras fibrosas que originam lamelas que penetram na glândula por suas duas porções laterais; unidos ao tendão subpélvico); ligamento médio (tecido conjuntivo elástico disposto no plano sagital mediano, dividindo o úbera em porções direita e esquerdo); cordões conjuntivos (tecido conjuntivo disposto dorsalmente à mama, fixando-a na parede do abdome); e fáscia superficial (tecido conjuntivo difuso que reveste as glândulas mamárias) (DAVIDSON \& STABENFELDT, 2008; FEITOSA, 2008; PARK \& LINDBERG, 2007).

\section{Sistema Circulatório}

A principal artéria para úbere da fêmea bovina é a Artéria pudenda externa. Ela atravessa o anel inguinal e dirige-se caudalmente para a base do úbere, formando uma flexura em " $\mathrm{S}$ ", bifurcando em uma Artéria mamária cranial e em uma Artéria mamária caudal. Esses dois vasos do úbere se anastomosam com a artéria que surge cranialmente, a Artéria epigástrica superficial caudal, a qual está em continuação com a Artéria epigástrica 
superficial cranial. Caudalmente, projeta-se também para o úbere o ramo labial ventral da Artéria pudenda interna (BRAGULLA \& KÖNIG; 2004).

O sistema venosos forma um plexo na base abdominal do úbere - na fáscia entre a glândula e a parede abdominal, que deverá receber a maior parte do sangue circulante das quatro glândulas. Esse plexo se estende anteriormente, dos dois lados nas veias abdominais subcutâneas que emergem do ponto localizado na parede abdominal na base da mama, e se dirige anteriormente para penetrar na cavidade torácica, em local próximo ao apêndice xifóide do osso externo, transformando-se na veia torácica interna para fixar-se na veia cava anterior. Esse mesmo plexo circulatório se estende posteriormente, formando outra via de circulação do sangue venoso do úbere, representado pelas veias pudendas externas. Por esses vasos, o maior volume de sangue circulante do úbere deixa o órgão, passando pelo canal inguinal, tendo trajeto paralelo às artérias, convergindo para a veia cava anterior, pela veia ilíaca externa (FEITOSA, 2008).

Finalmente o terceiro sistema venoso capacitado a circular o sangue venoso do úbere é representado pelas veias perineais. Em algumas vacas, é único para as duas metades do úbere. Essa veia se dirige em sentido dorsal e, sobre o ísquio, une-se à veia pudenda interna (FEITOSA, 2008).

A anastomose da Veia epigástrica superficial caudal com a Veia epigástrica superficial cranial, a denominada veia do leite, aumenta seu diâmetro durante a primeira lactação. Dessa forma, as valvas, nessas veias, permitem que o fluxo venoso seja realizado nas duas direções (BRAGULLA \& KÖNIG; 2004).

\section{Sistema Linfático}

O sistema linfático nas vacas centraliza-se nos linfonodos inguinais superficiais (ou retromamários) - localizados na base dos quartos posteriores da mama -; inguinais profundos e ilíacos externos (FEITOSA, 2008; PARK \& LINDBERG, 2007). 
Os vasos eferentes desses linfonodos passam direto do canal inguinal para os linfonodos inguinais profundos, mas também podem alcançar o linfonodo ilíaco externo (FEITOSA, 2008). Por meio dos troncos lombares, a linfa passa através da cisterna do quilo e do ducto torácico, penetrando depois no sistema venoso próximo da origem da veia cava cranial (PARK \& LINDBERG, 2007).

\section{Inervação}

Os nervos que inervam as várias estruturas do úbere são mistos quanto à origem, pois emanam da medula espinal (aferentes) e do sistema simpático (eferentes) (FEITOSA, 2008; PARK \& LINDBERG, 2007).

Os nervos espinais emergem da coluna lombar (ílio-hipogástrico, ilioinguinal e genitofemoral), por meio do canal inguinal, darão origem a terminações nervosas que inervam tanto a glândula mamária como a pele que os recobre. Os ramos ventrais do primeiro e segundo nervos lombares suprem uma pequena área da parte cranial do úbere, principalmente a pele. O nervo inguinal está localizado anteriormente aos vasos sanguíneos ilíacos externos quando eles descem através do anel inguinal interno, onde o nervo inguinal se divide em nervos cranial e caudal. O nervo inguinal cranial inerva a dobra do flanco e a parte cranial do quarto dianteiro e teto anterior (incluindo o ápice). O ramo cranial do nervo inguinal caudal do teto anterior e, em menor grau, o tecido glandular. O ramo caudal do nervo inguinal caudal inerva a área do linfonodo, o tecido glandular do quarto traseiro e a parte caudal do quarto dianteiro, o teto posterior e a pele do quarto traseiro, exceto a porção caudal acima da base do teto. A pele da parte caudal do úbere acima da base do teto. A pele da parte caudal do úbere acima do teto é inervada pelo nervo perineal superficial (BRAGULLA \& KÖNIG, 2004; PARK \& LINDBERG, 2007).

As fibras do sistema simpático provêm do plexo mesentérico (simpático lombar), passam atrvés do canal inguinal e induzem vasoconstrição (FEITOSA, 2008; PARK \& LINDBERG, 2007). 
O úbere é também formado com nervos ligados nos músculos lisos do sistema circulatório e dos músculos lisos dos dutos condutores de leite. No entanto, esta malha de nervos não controla diretamente o tecido produtor de leite (BRAGULLA \& KÖNIG, 2004; PARK \& LINDBERG, 2007).

\section{ASPECTOS FISIOLÓGICOS}

O crescimento mamário, sua diferenciação e lactação (secreção e saída do leite) envolvem os processos de mamogênese, lactogênese a galactpoese. A mamogênese refere-se ao crescimento e desenvolvimento da glândula mamária; lactogênese é o processo pelo qual as células alveolares mamárias adquirem a capacidade de secretar leite; e a galactopoese se refere à manutenção da secreção de leite e/ou intensificação da lactação estabelecida (PARK \& LINDBERG, 2007; RECCE, 2008).

\section{Mamogênese}

O processo de mamogênese inicia-se no desenvolvimento fetal do animal. Formando ao final, um sistema de ductos rodeado por tecido conjuntivo e adiposo (ENGELKING, 2010).

O desenvolvimento fetal da glândula mamária está sob controle genético. O desenvolvimento inicial do botão mamário está sob o controle do mesênquima mamário (tecido conjuntivo). Embora pouco se saiba sobre o desenvolvimento mamário fetal, não parece estar controlado por hormônios (DAVIDSON \& STABENFELDT, 2008).

No desenvolvimento embrionário da glândula mamária, uma linha de leite (ou mamária) aparece de cada lado da parede abdominal, paralela à linha média ventral (RECCE, 2008).

Aos 60 dias do desenvolvimento fetal, o botão mamário aprofunda-se na derme e a teta começa a se formar. A proliferação do ectoderma move-se mais profundamente para o mesênquima, formando um brotamento primário (ou 
botão). Cerca de 100 dias, a formação de canais começa na extremidade proximal do "botão" e prossegue gradualmente em direção à extremidade distal, produzindo uma abertura para o exterior. Botões secundários desenvolvem-se da extremidade proximal do botão primário, com as cavidades nos botões secundários desenvolvendo-se para dentro dos ductos principais. Eventualmente, desenvolvem-se as cisternas das glândulas e das tetas (PARK \& LINDBERG, 2007).

Quando o feto atinge os seis meses, o úbere já está com as quatro glândulas, o ligamento mediano, os tetos e a cisterna glandular formados (ELGENKING, 2010).

No processo de mamogênese, há importante atuação das Ativinas $\beta A$ e $\beta B$, pertencentes à superfamília da fatores de crescimento $\beta$ (TGF- $\beta$ ), agindo através dos receptores ActRIB e ActRIIA; e tendo efeitos antagonizados pelas inibinas e folistatinas (BLOISE, 2007).

Durante o crescimento corporal de novilhas, desde o nascimento até o primeiro parto, ocorrem duas fases distintas de desenvolvimento da glândula mamária. Na primeira fase, o desenvolvimento da glândula ocorre em intensidade proporcional aos demais tecidos corporais (fase de crescimento isométrico); na segunda fase, o crescimento da glândula mamária ocorre de duas a quatro vezes mais rápido que os demais tecidos corporais (fase de crescimento alométrico). A fase de crescimento isométrico está compreendida entre o nascimento da bezerra até a puberdade. Já a fase de crescimento alométrico está entre a puberdade e a época do parto (PARK \& LINDBERG, 2007; SCHAFHÄUSER JR., 2006).

Ao nascimento, a bezerra tem tetas e cisternas da glândula já prontas em forma. Os ductos mamários são curtos e estão confinados na região da cisterna da glândula. O estroma é bem organizado e entremeado com gordura (RECCE, 2008).

O aparelho mamário do nascimento até a puberdade sofre, relativamente, pouco desenvolvimento. A velocidade do crescimento mamário está de acordo com a velocidade do crescimento corporal, até o início da 
atividade ovariana que precede a puberdade. Até então, a mamária é uma glândula da pele que responde aos hormônios sexuais femininos, presentes em baixas concentrações até cio (PARK \& LINDBERG, 2007; RECCE, 2008).

Com o início do ciclo estral (puberdade) há liberação do hormônio folículo-estimulante (FSH) e hormônio luteinizante (LH) pela glândula pituitária anterior, devido ao estímulo de hormônio regulador das gonadotropinas (GnRH) liberado pela glândula hipotalâmica. A atividade do FSH sobre o ovário, durante a fase folicular, influencia as células da granulosa do ovário converteram androgênios (produzidos pela teca interna do folículo, influenciados por LH) em estrogênios. Já a atividade do LH sobre o ovário, durante a fase luteínica, influencia o crescimento de corpos lúteos no ovário (pela luteinização da granulosa); desta forma, essas células convertem os estrogênios em progesterona (GRECO \& STABENFELDT, 2008; RECCE, 2008).

A ação conjunta de estrogênio e progesterona nessa fase causa a estimulação das células glandulares (proliferação). Porém, o trabalho desses dois hormônios depende do sinergismo dos mesmos com a somatotropina $(\mathrm{STH})$ e a prolactina (PRL), ambos hormônios da pituritária anterior; esse sinergismo promove alongamento, espessamento e ramificações dos ductos mamários. A diferenciação dos ductos em alvéolos continua com cada ciclo estral posterior. O máximo de crescimento de lóbulos e alvéolos nos ciclos estrais somente ocorre com cerca de 30 a 36 meses de idade. Soma-se aos hormônios anteriormente descritos, a ação dos glicocorticóides. (ENGELKING, 2010; RECCE, 2008).

A maior parte do crescimento da glândula mamária se dá durante a gestação, em resposta às maiores concentrações hormonais de estrogênio (produzido também pela placenta de bovinos), progesterona, somatotropina e prolactina. Após três ou quatro meses de gestação, por ação do estrogênio, somatotropina e glicocorticóides, os ductos mamários se alongam novamente e os alvéolos proliferam-se e substituem o tecido adiposo, até então, em grande quantidade no estroma. Ao final do sexto mês, com efeitos adicionais do prolactina e do progesterona, observa-se um extenso desenvolvimento 
lobuloalveolar; com células que sintetizam e secretam leite ativamente (ENGELKING, 2010; REECE, 2008).

\section{Lactogênese e Galactopoese}

Os processos de lactogênese e galactopoese compreendem a aquisição da capacidade das células alveolares da glândula mamária de produzir leite e secretá-lo; sendo um total desafio para o metabolismo energético da fêmea lactante (CAMPOS et al, 2005; REECE, 2008).

Durante esses eventos, haverá um aumento na atividade enzimática mamária e diferenciação das organelas celulares dos alvéolos. Devido a isso, uma série de adaptações fisiológicas ocorrerá no animal, por meio de um controle endócrino; objetivando a produção de leite em detrimento a outras atividades metabólicas (crescimento e atividade reprodutiva). Apesar disso, a homeostasia do animal deve estar garantida. Essas características se relacionam às mudanças nas concentrações séricas hormonais do animal durante a lactogênese, favorecendo o suprimento de nutrientes para a glândula mamária em detrimento a outros tecidos (CAMPOS et al, 2005; ENGELKING, 2010; REECE, 2008).

Um dia antes do parto, o hormônio prostaglandina F2a aumenta consideravelmente sua concentração sérica; resultando em lise do corpo lúteo. Conseqüentemente, há uma queda drástica na produção de progestrona, o que viabiliza a formação de sítios de ligação do prolactina no tecido mamário e dessaturação de sitos de glicocorticóides. Une-se a esses eventos, uma produção máxima, um mês antes do parto, de estrogênio (que estimula a síntese de prolactina); e uma onda de somatotropina (direcionando nutrientes para a glândula mamária) (EILER, 2007; GRECO \& STABENFELDT, 2008).

Os principais hormônios requeridos para a mantença da lactação são: prolactina, somatotropina, insulina, paratormônio, adrenocorticotrópico (conseqüentemente, glicocorticóides) e tireoestimulante (conseqüentemente, 
triiodotironina e tetraiodotironina) (CAMPOS et al, 2005; ENGELKING, 2010; REECE, 2008).

\section{Prolactina (PRL)}

A prolactina é um hormônio peptídico produzido na hipófise anterior. Apresenta funções no desenvolvimento de tecido mamário (mamogênese), início e mantença da lactação (lactogênese e galactopoese) (ELGELKING, 2010).

Como hormônio fundamental, tem papel importante na diferenciação das células da glândula mamária e controle de passos bioquímicos envolvidos na síntese do leite. Induz o acúmulo de RNAm da caseína, estimulando a expressão de genes dessa proteína e de outros genes (EILER, 2007; REECE, 2008).

Além de estímulos internos, esse hormônio tem sua liberação influenciada também pelos estímulos sensoriais durante o manejo do teto na ordenha. Os estímulos são conduzidos até o hipotálamo, onde a síntese de dopamina é bloqueada (já que a dopamina é um inibidor de secreção de prolactina); e há estímulo para a produção de peptídeo intestinal vasoativo (um dos estimulantes para liberação de prolactina) (GRECO \& STABENFELDT, 2008).

A prolactina age sinergicamente com a liberação do hormônio tireoestimulante; além de que, um importante inibidor de sua ação é o 2-Br-aergocryptine-methansulphonate (KARGS e SCHAMS, 1974).

\section{Hormônio Somatotrópico (STH)}

O hormônio somatotrópico, também conhecido como hormônio do crescimento $(\mathrm{GH})$ ou somatotropina (ST) é uma pequena molécula peptídica, podendo por isso ser ainda chamado de hormônio protéico. É sintetizado e 
liberado pela hipófise anterior em resposta ao hormônio regulador do hormônio somatotrópico, produzido e liberado pelo hipotálamo (ELGELKING, 2010).

O hormônio somatotrópico é um hormônio hiperglicemiante (aumentando a glicogenólise) e favorecendo um maior aporte de glicose ao tecido mamário; isso, sem reduzir os níveis basais de glicose, já que reduz a oxidação de glicose em outros tecidos. Participa do metabolismo lipídico do organismo animal, promovendo a lipólise (liberando ácidos graxos livres na circulação sistêmica) e aumentando a quantidade de ácidos graxos de cadeia longa no leite. Apesar de aumentar os valores séricos de cálcio, magnésio e fosfato; não modifica os níveis de mineral na secreção láctea (GRECO \& STABENFELDT, 2008; REECE, 2008; RODRIGUES, 2008).

Além disso, o hormônio somatotrópico influencia diretamente no equilíbrio entre células alveolares secretoras e células alveolares mortas por meio de sua ação na mitose celular em tecidos com células somáticas (BOUTINAUD, 2003).

O uso de hormônio somatotrópico bovino exógeno, com a finalidade de aumentar a produção leiteira, foi um dos primeiros potenciais produtos vindos da biotecnologia de produção animal; e tem obtido resultados sem alteração do valor genético do animal. Porém, os resultados não são devidos há uma alta proliferação de células alveolares, e sim, pelo maior compartilhamento dos nutrientes disponíveis dos tecidos corpóreos para a síntese do leite. Em contrapartida, o uso inconsciente e indiscriminado desse hormônio pode gerar danos à fisiologia endócrina natural do animal, já que o sistema de feedback negativo proporcionado pela alto nível sérico do hormônio, pode gerar uma hipoplasia de células somatotrópicas da hipófise anterior (BAUMAN, 1992; REECE, 2008; RODRIGUES, 2008). 
Insulina

A insulina é um hormônio peptídico produzido pelas células $\beta$ das ilhotas pancreáticas. Age em resposta à ingestão de alimento, ou seja, período de anabolismo (EILER, 2007).

O efeito da insulina é sobre o metabolismo de carboidratos, lipídeos e proteína. Promovendo a entrada de glicose dentro de células do organismo, a insulina estimula glicogênese e lipogênese, além de desviabilizar enzimas que catalisam a glicogenólise. Além disso, aumenta o transporte da maioria dos aminoácidos para o músculo, estimula síntese de proteína e inibe catabolismo protéico; induz a síntese de lípase lipoproteica, inibe a lípase intracelular e aumenta esterificação de ácidos graxos. Ou seja, baixa as concentrações sanguíneas de glicose, ácidos graxos e aminoácidos e promove a conversão intracelular desses compostos em sua forma de armazenamento (ENGELKING, 2010).

Na espécie bovina, a glândula mamária utiliza glicose, acetato, $\beta-\mathrm{OH}-$ butirato e triglicerídeos de forma independente da insulina; desta forma, as concentrações de insulina são baixas no início da lactação (quando a produção de leite é alta, ou seja, as células alveolares mamárias necessitam de mais glicose - que não se direciona tanto a outros tecidos que necessitem da insulina), e aumentam gradativamente até o fim da lactação (quando a produção de leite é baixa, ou seja, as células alveolares mamárias não necessitam da mesma quantidade de glicose anteriormente - que se direcionará mais para outros tecidos) (CAMPOS et al, 2005; GRECO \& STABENFELDT, 2008; REECE, 2008).

\section{Paratormônio (PTH)}

O paratormônio uma hormônio peptídico produzido pelas células da paratireóide liberado para manter a homeostasia mineral sérica do organismo (ENGELKING, 2010). 
O paratormônio tem ação direto sobre o metabolismo de cálcio nos ossos; promovendo atividade aumentada de osteoclastos (gerando lise de matriz extracelular óssea, com conseqüente liberação de minerais para circulação sanguínea); e atividade diminuída de osteoblastos (evitando o uso de minerais séricos para síntese de matriz extracelular óssea). Além disso, esse hormônio age nos túbulos contorcidos dos rins para aumentar a absorção de cálcio. Como efeito secundário no intestino, converte a vitamina $D$ em sua forma ativa (1,25 diidroxicolecalciferol) estimulando a absorção de cálcio pelos enterócitos (GRECO \& STABENFELDT, 2008; REECE, 2008).

Em virtude do elevado conteúdo de cálcio no leite, a concentração de 1,25 diidroxicolecalciferol é aumentado durante a lactação (ELGELKING, 2010).

\section{Hormônio Adrenocorticotrópico (ACTH)}

O hormônio adrenocorticotrópico é um hormônio peptídico produzido pela porção anterior da hipófise, e liberado por estímulo da liberação do hormônio regulador do hormônio adrenocorticotrópico (ACTHRH), produzido e liberado pelo hipotálamo (EILER, 2007).

Esse hormônio se torna essencial para regular a liberação de corticoesteróides (glicocorticóides e mineralocorticóides) pela córtex da glândula adrenal. Durante a lactogênese, o principal corticoesteróide é o cortisol. (CAMPOS et al, 2005; REECE, 2008).

O aumento nos níveis séricos de cortisol no final da gestação, parto e durante a lactação é considerado normal (ANTONIAZZI et al, 2009; PAIVA et al, 2006).

O cortisol é um mediador de metabolismo intermediário; estimulando gliconeogênese hepática (envolvendo conversão de aminoácidos em carboidrato) e aumentando os níveis de glicose sanguínea; inibe a captação e metabolismo de glicose principalmente em músculo e células adiposas; além de aumentar a taxa de lipólise. Desta forma, disponibiliza mais glicose e ácidos 
graxos para síntese láctea (ENGELKING, 2010; GRECO \& STABENFELDT, 2008).

A maior concentração de cortisol encontra-se durante a segunda semana de lactação; onde, além de participar do metabolismo de carboidrato e lipídico, induz a diferenciação do retículo endoplasmático rugoso e do aparelho de Golgi das células alveolares (CAMPOS et al, 2008; GRECO \& STABENFELDT, 2008).

Não pode-se deixar de relacionar a alta taxa de cortisol sérico durante a lactação da fêmea ao stress sofrido pelo mesma durante a ordenha. O stress crônico aumenta significativamente o nível plasmático médio de cortisol (JUNIOR et al, 2003).

Hormônio Tireoestimulante (TSH)

O hormônio tireoestimulante é um hormônio peptídico produzido pela hipófise anterior e secretado pela ação do hormônio regulador do hormônio tireoestimulante, produzido e liberado pelo hipotálamo (REECE, 2008).

O hormônio tireoestimulante atua diretamente nas células da glândula tireóide estimulando a produção de colóide e liberação dos hormônios tireóideos. Os hormônios tireóideos são hormônios amina derivados do aminoácido tirosina em conjugação com moléculas de iodo. Há dois desses hormônio: tetraiodotironina (T4 - formado por duas moléculas de tirosina e quatro moléculas de iodo) e triiodotironina (T3 - formado por duas moléculas de tirosina e três moléculas de iodo). O mais metabolicamente ativo é o T3 (COLODEL, 2005; NASCIMENTO, VIEIRA e SILVA, 2006).

Os hormônios tireóideos têm capacidade de aumentar a atividade metabólica e consumo de oxigênio da maioria dos tecidos do corpo. Como a produção e secreção láctea, pelo animal, dependem de árdua atividade celular dos alvéolos mamários, encontrar-se-ia uma correlação positiva entre esses hormônios e a produção leiteira; porém, estudos afirmam que há correlação negativa entre esses níveis (COLODEL, 2005; REECE, 2008). 
Os hormônios tireoidianos, além de participarem do desenvolvimento da glândula mamária, aumentam a síntese e a secreção de algumas proteínas do leite, como a alfa-lactoalbumina. Além disso, para que os principais hormônios galactopoéticos, tais como o $\mathrm{GH}$ e a PRL, atuem na glândula, é essencial a participação dos hormônios tireoidianos. O GH, a PRL e a T4 aumentam a atividade da 5'desiodase na glândula mamária, enzima que converte a tiroxina (T4) em triiodotironina (T3), forma metabolicamente ativa do hormônio tireoidiano (LEITE et al, 2007).

Estudos afirmaram que T4 tem nível circulante maior em fêmeas bovinas me primeira lactação que em fêmeas com ordem de lactação mais avançada (NASCIMENTO, VIEIRA e SILVA; 2006).

\section{Remoção de Leite}

A secreção do leite é um processo contínuo e está sob controle de um feedback negativo responsivo à alta pressão intra-alveolar. Assim a capacidade de armazenagem de leite determina a velocidade de secreção e a produtividade da glândula (ELGENKING, 2012). Para que a lactogênese possa ser mantida, o leite deve ser retirado da glândula mamária por mamada ou ordenha. Se o leite não for removido dentro de 16 horas em vacas leiteiras, a síntese de leite pode ser suprimida (DAVIDOSN \& STABENFELDT, 2008).

A maior parte do leite contido no úbere de uma vaca leiteira no momento da ordenha está localizado dentro dos ductos e dos alvéolos. A movimentação de leite dentro da cisterna da glândula na mamada ou na ordenha é lenta, e menos leite seria obtido durante a ordenha de uma vaca se a drenagem do leite fosse um processo passivo (DAVIDOSN \& STABENFELDT, 2008).

Para facilitar o processo de remoção do leite, as células mioepiteliais rodeiam os alvéolos e ductos. As células mioepiteliais são particularmente responsivas à oxigenação e, de fato, se contraem quando exposta ao hormônio. A síntese e a liberação de oxitocina pela hipófise posterior é iniciada por um reflexo neuroendócrino que envolve a estimulação táctil do úbere 
através da sucção executada pelo recém-nascido ou por estimulação manual da lavagem do úbere antes da ordenha. O estímulo sensorial a partir do úbere é transportado através da medula espinhal até o hipotálamo. Os neurônios nos núcleos paraventricular e supra-óptico são estimulados para sintetizar e liberar oxitocina através das terminações nervosas que passam pela eminência média. Outros estímulos sensoriais que promovem liberação de oxitocina incluem os auditivos, os visuais ou o olfatórios que ocorrem próximo ou dentro do local da ordenha (REECE, 2008).

A liberação de oxitocina ocorre dentro de segundos após a chegada do estímulo ao hipotálamo; a pressão aumentada dentro da glândula mamária torna-se evidente dentro de um minuto após a estimulação à medida que o leite é forçado para fora dos alvéolos e ductos por contrações das células mioepiteliais; isto é chamado de "descida do leite". O aumento de pressão dentro do úbere ocorre dentro de 1 minuto após a estimulação. A liberação de oxitocina demora apenas poucos minutos (DAVIDSON \& STABENFELDT, 2008; DUKES, 1996).

A retirada freqüente do leite produz aumento das taxas de secreção e diminuição das pressões intramamárias. Existe também a possibilidade de que componentes específicos do leite possam agir dentro da célula mamária para inibir sua própria secreção independentemente da pressão intramamária (ENGELKING, 2010).

\section{Ciclo de Lactação}

A produção de leite tende a aumentar nas primeiras 3 a 4 semanas de lactação e então começa a declinar lentamente até o final da lactação. Os animais normalmente estarão "secos" após 305 dias de período lactacionais; os índices de produção são calculados com base nas quantidades de quilos de leite e de gordura produzidos. A pressão retrógrada dentro do alvéolo causada pelo leite inibe gradualmente a secreção do leite pelas células epiteliais alveolares, com resultante regressão das células alveolares e dos pequenos 
ARAÚJO, G.D. et al. Aspectos morfológicos e fisiológicos de glândulas mamárias de fêmeas bovinas - revisão de literatura. PUBVET, Londrina, V. 6, N. 36, Ed. 223, Art. 1478, 2012.

ductos. O processo denominado involução, frequentemente requer pelo menos 1 mês, havendo necessidade de um período de 6 semanas no mínimo de intervalo entre uma lactação e outra. Dentro de um período de 1 a 2 meses os sistemas secretor (alvéolos) e excretor (ductos) regridem e são substituídos (DAVIDOSN \& STABENFELDT, 2008; PARK \& LINDBERG, 1996; REECE, 2008).

\section{REFERÊNCIAS}

ANTONIAZZI, A. Q.; LISTON, M. A.; GABRIEL, A. L.; BARCELLOS, A. R.; CECIM, M. Indução do parto de bovinos aos 270 dias de gestação com a utilização prévia de glicocorticóide de longa ação e a transferência de imunidade passiva. Acta Scientiarum Animal Sciences, v. 31, n. 1, p. 103-109, 2009. Disponível em: http://periodicos.uem.br/ojs/index.php/ActaSci AnimSci/article/viewFile/398/398. Acesso em: 20 ago. 2012.

BAUMAN, Dale E. Bovine Somatotropin: Review of na Emerging AnimalTechnology. Journal of Dairy Science, v. 75, n. 12, p. 3432-3451, 1992. Disponível em: http:// jds.fass.org/cgi/content/abstract/75/12/3432. Acesso em: 20 ago. 2012.

BLOISE, Enrico. Expressão e Localização de $\beta A / \beta B$ Ativina, Seus Receptores ActRIB e ActRIIA, de a-Inibina e de Folistatina na Glândula Mamária Bovina Gestacional. Dissertação (Mestrado em Ciências Biológicas) - Faculdade de Fisiologia e Farmacologia, Universidade Federal de Minas Gerais, Belo Horizonte, 2007. Disponível em: http://www.bibliotecadigital.ufmg.br. Acesso em: 10 ago 2012.

BOUTINAUD, M; ROUSSEAU, C.; KEISLER, D. H.; JAMMES, H. Growth Hormone and Milking Frequency Act Diffrently on Goat Mammary Gland in Late Lactation. Journal of Dairy Science, v. 86, n. 2, p. 509-520, 2003. Disponível em: http://jds. fass.org/cgi/content/abstract/86/2/509. Acesso em: 12 ago. 2012.

BRAGULLA, H. \& KÖNIG, H. E. Glândula Mamária nos Animais Domésticos (Mamma). In: KÖNIG, H. E.; LIEBICH, H. Anatomia dos Animais Domésticos Vol.2 - Órgãos e Sistemas. Porto Alegre: Artmed, 2004, p. 335-342.

CAMPOS, R.; LACERDA, L. A.; TERRA, S. R.; GONZÁLEZ, F. H. D. Parâmetros hematológicos e níveis de cortisol plasmático em vacas leiteiras de alta produção no Sul do Brasil. B. J. vet. Res. Anim. Sci., v. 45, n. 5, p. 354-361, 2008. Disponível em: http://www.revistasusp.sibi .usp.br/pdf/bjvras/v45n5/04.pdf. Acesso em: 19 ago. 2012.

COLODEL, Márcia Moleta. Concentrações Séricas de Triiodotironina ( $\left.\mathbf{T}_{3}\right)$ e Tetraiodotironina $\left(\mathrm{T}_{4}\right)$ em Ovelhas da Raça Crioula Lanada Durante a Gestação e Lactação. Dissertação (Mestrado em Ciências Veterinária) - Faculdade de Medicina Veterinária, Universidade do Estado de Santa Catarina, Lages, 2005. Disponível em: http://lakh.unm.edu/handle/10229/16328. Acesso em: 12 ago. 2012.

DAVIDSON, A.P.; STABENFELDT, G.H. Glândula Mamária. In: CUNNIGHAM, J. G. Tratado de Fisiologia Veterinária. 3 ed. Rio de Janeiro: Guanabara Koogan, 2008, p. 417-431. 
DYCE, K. M.; SACK, W. O.; WENSING, C. J. B. O Úbere dos Ruminantes. In: DYCE, K. M.; SACK, W. O.; WENSING, C. J. B. Tratado de Anatomia Veterinária. 2 ed. Rio de Janeiro: Guanabara Koogan, 1997, p. 567-573.

EILER, H. Glândulas Endócrinas. In: DUKES, H. H. Fisiologia dos Animais Domésticos. 12 ed. Rio de Janeiro: Guanabara Koogan, 2007, p. 577-622.

ENGELKING, L. R. Glândulas Mamárias. In: ENGELKING, L. R. Fisiologia Endócrina e Metabólica em Medicina Veterinária. 2 ed. São Paulo: Roca, 2010, p. 44-49.

FEITOSA, F. L. F. Semiologia da Glândula Mamária de Éguas, Cadelas e Gatas. In: FEITOSA, F. L. F. Semiologia Veterinária: A Arte do Diagnóstico. 2 ed. São Paulo: Roca, 2008, p. 321323.

GRECO, D.; STABENFELDT, G. H. Endocrionologia. In: CUNNIGHAM, J. G. Tratado de Fisiologia Veterinária. 3 ed. Rio de Janeiro: Guanabara Koogan, 2008, p. 333-381.

JUNIOR, I. A.; ARCARO, J. R. P.; POZZI, C. R.; FAGUNDES, H.; MATARAZZO, S. V.; OLIVEIRA, C. A. Teores plasmáticos de hormônios, produçãoe e composição do leite em sala de espera climatizada. Revista Brasileira de Engenharia Agrícola e Ambiental , v. 7, n. 2, p. 350354, 2003. Disponível em: http://www.scielo.br/scielo .php?pid=S1415-4366200300020002 8\&script=sci_arttext\&tlng=pt. Acesso em: 12 ago. 2012.

JUNQUEIRA, L. C.; CARNEIRO, José. Histologia Básica. 9 ed. Rio de Janeiro: Guanabara Koogan, 1999, p. 367-388.

KARG, H; SCHAMS, D. Prolactin Release in Cattle. J. Reprod. Fert., v. 39, p. 463-472, 1974. Disponível em: http://www.reproduction-online.org/cgi/content/abstract/39/2/463. Acesso em: 10 ago. 2012.

LEITE, E. D.; FREITAS, E. S.; SOUZA, C. A.; OCARINO, N. M.; CASSALI, G. D.; FERREIRA, E.; GOMES, M. G.; SERAKIDES, R. Proliferação, Apoptose e Histomorfometria da Glândula Mamária de Ratas Tratadas com Tiroxina na Lactação e ao Desame e Desenvolvimento dos Filhotes. Arquivo Brasileiro de Endocrinologia e Metabolismo, v. 51, n. 6, p. 1000-1006, $2007 . \quad$ Disponível em: http://www.scielo.br/scielo.php?script=sci_arttext\&pid=S000427302007000600016\&lng =en\&n rm=iso\&tlng=pt. Acesso em: 12 ago 2012.

NASCIMENTO, M. R. B. M.; VIEIRA, R. C.; SILVA, G. C. Efeitos de mês, Ordem e Estádio de Lactação Sobre os Hormônios Tireoideanos de Vacas e Novilhas Holandesas. Archieves of Veterinary Science, $v$. 11, n. 2, p. 55-60, 2006. Disponível em: http://ojs.c3sl.ufpr.br/ojs2/index.php/veterinary/article/view/6786/48 44. Acesso em: 12 ago 2012.

PAIVA, F. A.; NEGRÃO, J. A.; NETTO, A. S.; PORCIONATO, M. A. F.; LIMA, C. G. Efeito do manejo de aleitamento nos níveis de cortisol no metabolismo e na produção de leite de vacas holandesas. Revista Brasileira de Zootecnia, v. 35, n. 6, p. 2376-2380, 2006. Disponível em: http://www.scielo.br/pdf/rbz/v35n6/25.pdf. Acesso em: 12 ago 2012.

PARK, C. S.; LINDBERG, G. L. Glândula Mamária e Lactação. In: DUKES, H. H. Fisiologia dos Animais Domésticos. 12 ed. Rio de Janeiro: Guanabara Koogan, 2007, p. 670-690.

REECE, W. O. Lactação. In: REECE, W. O. Anatomia Funcional e Fisiologia dos Animais Domésticos. 3 ed. São Paulo: Roca, 2008, p. 418-431. 
RODRIGUES, M. Impacto da utilização da somatrotopina bovina (bST) sobre a produção de leite e a avaliação genética de bovinos da raça Holandesa. Dissertação (Mestrado em Ciências Biológicas) - Departamento de Genética, Faculdade de Medicina de Ribeirão Preto, Ribeirão Preto, 2008. Disponível em: http://www.rge.fmrp.usp.br/pg/dissertacao/impacto-da-utilizacao-daso matotropina-bovinabst-sobre-a-producao-de-leite-e-a-avaliacao-genetica-d. Acesso em: 10 ago 2012.

SCHAFHÄUSER JR., J.. Desenvolvimento da Glândula Mamária Durante a Recria e sua Influência no Potencial Produtivo de Fêmeas Leiteiras. Revista da FZVA, v. 13, n. 1, p. 128148, 2006. Disponível em: http://revistaseletronicas.pucrs.br/ojs /index.php/fzva/article/viewFile/2346/1832. Acesso em: 11 ago 2012. 